Paulina Węgrzyn (1) Uniwersytet Pedagogiczny, Kraków paulina.wegrzyn@up.krakow.pl

\title{
La imagen del ,otro" en la literatura argentina
}

\section{Resumen:}

Argentina ha sido uno de los países americanos que notó un mayor flujo migratorio a lo largo de los siglos XIX y XX. La colonización empezada por los pobladores blancos europeos en el siglo XVI culminó con la creación del estado argentino en 1810, cuyos políticos decidieron dejar atrás todo el pasado colonial, rechazando no solamente el sistema del gobierno sino también todas las manifestaciones de las culturas autóctonas. En busca de la civilización miraron hacia centenarias culturas europeas y abrieron las puertas a todos sus representantes que quisieran poblar su territorio. Los europeos iban a traer consigo la cultura y de esa forma "civilizar" las tierras argentinas. Sin embargo, la realidad resultó ser diferente. Los que abandonaron Europa en pocos casos provenían de la clase alta de la sociedad. Pobres e incultos trabajadores arribaron a la costa argentina buscando una vida mejor. De una promesa de civilización se convirtieron en un peligro para la naciente identidad argentina. La dura realidad encontró su reflejo en la literatura. La inicial admiración hacia "el otro" que está visible en las obras de los grandes pensadores y legisladores de aquellos tiempos fue sustituida por la negación y la burla. Del símbolo de bienestar y de lo intelectual, "el otro" primero pasó a ser un objeto de broma, luego le fue asignado el papel del protagonista negativo, que constituía un elemento destructivo en la sociedad. Aunque con el tiempo el destructor se convertirá en su representante. Ya que personificará el origen de la nueva sociedad argentina.

Palabras clave: la figura del "otro", la literatura argentina, la inmigración 


\section{Abstract: \\ The Image of "the Foreigner" in the Argentinian Literature}

Argentina was one of the American countries which recorded the largest percentage of immigrants arriving from Europe at the turn of the $19^{\text {th }}$ and $20^{\text {th }}$ centuries. The process of colonization started by white settlers (Spaniards) in the $16^{\text {th }}$ century was finally finished in 1810 with the establishment of a new state of Argentina, a political unit which decided to reject the past with its whole colonial history, from the system of government to the elements of local cultures. The source of inspiration for a new country was Europe with its centuries-old various cultures and, as a result, it opened up for Europeans wishing to settle on the Argentinian territory. They were expected to introduce their culture and civilize the new homeland, but the reality was quite different. The newcomers, who were mainly working class, poor, uneducated and often illiterate people, came to Argentina to look for work and better living conditions, and instead of building a new culture they soon posed a threat to an emerging national identity. This reality was reflected in literature, especially in the works of writers, philosophers and legislators, in which the initial admiration for immigrants was soon replaced with the rejection and 'the foreigner'. Thus, 'the foreigner', who previously symbolized intellectual values in almost every aspect of life, became an object of ridicule and quickly turned into a negative figure. With time, however, the attitude towards 'the foreigner-destroyer' changed and they grew to become a symbol of national identity.

Key words: the image of foreigner, immigration, Argentinian literature

Aunque por primera vez la figura del inmigrante en la literatura argentina apareció en el teatro, ${ }^{1}$ será la novela el género en el cual "el otro", de un personaje episódico, con el tiempo se convertirá en el principal protagonista de tantas obras de la narrativa argentina creadas en las últimas décadas del siglo XIX y a principios del siglo XX. Por esa razón, en este trabajo nos centramos en primer lugar en las novelas, haciendo también referencia a algunos ensayos y textos teóricos que

${ }^{1}$ „El otro” - Marcos Figueira, apareció en una obra anónima del año 1792, titulada "El amor de la estanciera". Es un inmigrante de origen portugués que se convierte en objeto de burla por ser distinto de los demás. En los años siguientes ironizar sobre el "otro" será la principal manera de creación del personaje, que dominará en el sainete. 
nos permiten entender mejor el contexto histórico y social en el que fueron creadas las ficciones literarias.

Como marco temporal tomamos los primeros cien años de la historia de Argentina, para señalar ciertas tendencias y mostrar obras representativas que nos permitan observar cómo evolucionó la manera de presentar al "otro" en la literatura. En conclusión, mencionaremos algunas obras creadas con ocasión del famoso Centenario ${ }^{2}$.

Para definir quién es considerado "el otro" dentro del mundo de la novela argentina, en primer lugar, habría que responder a una pregunta básica, tantas veces planteada durante los debates acerca de la argentinidad: ¿quiénes son los argentinos?

Una humorística definición dice que los argentinos son italianos que se creen franceses, pero hablan español. Y aunque es solamente una anécdota, es una muestra de los distintos orígenes de la nación argentina. La nación que surgió en el siglo XIX del crisol de culturas y razas: de la autóctona de los indígenas, de la criolla de los descendientes de los españoles que colonizaron el continente en los siglos posteriores y de la europea, de los inmigrantes que arribaron en masa a las costas de Argentina a lo largo del siglo XIX.

Mariano Moreno, el iniciador de la política migratoria ya en 1810 , el año en el que Argentina se independizó de la corona española, postulaba poblar el desierto, las vastas tierras argentinas hasta aquel entonces amenazadas con la presencia de los indios. Y así, durante el régimen de Rivadavia fue iniciada la política proinmigratoria, de atraer gente de fuera que pudiera poblar, construir y desarrollar la nueva Argentina. Aunque esa visión fue rechazada durante la dictadura rosista, en las décadas siguientes fue retomada con nuevo entusiasmo.

La constitución del año 1853 autorizó la entrada de los inmigrantes en el país, creando condiciones favorables para las personas de fuera que quisieran empezar una nueva vida al otro lado del océano.

${ }^{2}$ La celebración de los 100 años de la existencia del estado argentino fue una ocasión para reflexionar acerca del pasado y el presente de Argentina, fue un tiempo de debates, de análisis fríos de la sociedad, cuyos reflejos encontramos en la literatura. 
Los políticos dirigieron sus miradas hacia los viejos países europeos, viendo en sus habitantes la promesa de un futuro rápido desarrollo del país. El reflejo de aquellos tiempos lo encontramos en las discusiones teóricas de los grandes pensadores de la época que debatían sobre las mejores vías que debía seguir la joven nación argentina para convertirse en un país con futuro, próspero y civilizado.

Los primeros intentos de definir el concepto de la identidad propia fueron tomados en el Salón Literario de Marcos Sastre. Los encuentros, inaugurados en 1837 por los jóvenes representantes de la élite bonaerense, de su carácter ligero de intercambio de ideas y pensamientos, pasaron a ser fervientes discusiones acerca del concepto de la argentinidad.

Los representantes de la generación del 37 estaban de acuerdo en una cosa: Argentina debía adoptar los modelos culturales europeos y la mejor manera para ello fue a través de sus representantes, que podían traer consigo la civilización y la tradición europeas. Las repercusiones del dicho pensamiento las veremos en las actuaciones del gobierno.

Una de las obras clave para entender las tensiones y preocupaciones de aquellos tiempos es Facundo de Domingo Faustino Sarmiento, quien fue testigo de los grandes cambios que ocurrían en el suelo argentino, él mismo vivió el fin de una época y pudo participar activamente en la creación de la nueva realidad, nos ofrece un testimonio del pensamiento de sus contemporáneos.

Ya el mismo subtítulo de la obra Civilización y Barbarie en las Pampas Argentinas anuncia el principal conflicto en la sociedad argentina entre la civilización, representada por los habitantes de la ciudad, entre ellos cultos inmigrantes asentados en Argentina, y la barbarie que se esconde en la pampa argentina. En su obra, Facundo Quiroga personifica todos los rasgos negativos atribuidos al inculto mundo de la pampa, entre otros la violencia del gaucho y la ignorancia del caudillo. A través de su personaje Sarmiento divaga acerca de la historia de Argentina. No le hace responsable de sus acciones al caudillo sino a la herencia y al medio ambiente en el que se formó. Al describir al caudillo dice: "Facundo, expresión fiel de una manera de ser de un pueblo, de sus preocupaciones e instintos; Facundo, en fin, siendo lo 
que fue, no por accidente de su carácter, sino por antecedentes inevitables y ajenos a su voluntad" (Sarmiento, 1986: 48).

Según Sarmiento, llamar Argentina un pueblo civilizado es una utopía. Para civilizar el país es necesario derrotar las fuerzas bárbaras, representadas en la figura de Quiroga, rechazar la ignorancia y el atraso. Y dirigir la vista hacia Europa, inspirarse en las milenarias culturas del viejo continente y poblar.

"El otro" en las obras de Sarmiento de mitad del siglo XIX simboliza el desarrollo, el conocimiento y la cultura.

Esta admiración hacia lo europeo, hacia el cosmopolitismo de grandes ciudades y hacia sus habitantes procedía de una visión errónea de Europa. Los inmigrantes europeos que llegaron a Argentina en la primera mitad del siglo XIX eran profesionales, comerciantes, gente con seguridad económica. Representaban solamente una de las caras de la cultura europea. Grande será la decepción cuando en vez de élites, a las costas argentinas empiecen a arribar los inmigrantes de bajas capas sociales, sin fondos, sin formación, igual podríamos atrevernos a decir sin cultura. Pero esta será la preocupación de los años posteriores.

Una visión similar a las ideas sarmientinas acerca de la superioridad cultural del "otro" en la sociedad nos la ofrece Esteban Echeverría en su obra El matadero.

Aunque publicada más tarde, en 1871, en realidad fue escrita mucho antes, por el año 1839/1840, lo que significa que Echeverría no podía conocer la obra de Sarmiento. ${ }^{3}$

Sin embargo, curiosamente los dos coinciden en su diagnóstico acerca del estado del país y muestran soluciones parecidas. Mencionado en el título de la obra, el matadero es un tipo de un mundo aparte que en la realidad equivale a la vida en la ciudad de Buenos Aires. Los trabajadores simbolizan la barbarie y la incultura. Son ellos los responsables de la muerte de un transeúnte, un joven que representa la cultura de las ciudades.

\footnotetext{
${ }^{3}$ La primera publicación de Facundo tuvo lugar en 1845.
} 
En la misma línea de pensamiento se inscribe Amalia de José Mármol.

Sarmiento, Echeverría y Mármol representan el pensamiento político social del romanticismo argentino que se caracterizaba por el rechazo de todo lo que venía del pasado (el indio, el gaucho, el caudillo). Según los románticos argentinos el futuro del país estaba en el acto de civilizar, mediante la inmigración. En sus obras está visible el conflicto entre la civilización europea contra la barbarie americana. Los inmigrantes, portadores del progreso y de la cultura de los tan admirados países del viejo continente, debían causar un rápido desarrollo del país. Mientras los símbolos de los viejos tiempos, las figuras del gaucho o del indio, fueron asociadas con el atraso y la reacción.

Sin embargo también hubo autores que al describir la misma realidad argentina ofrecían una visión completamente diversa a la de los novelistas románticos. Reconociendo la simplicidad de la cultura autóctona no la despreciaban ni veían en ella un peligro para la naciente nación argentina. Estas voces podemos observarlas entre los representantes de la poesía gauchesca.

José Hernández en Martín Fierro defiende la figura del gaucho y censura la actitud hostil del supuesto "hombre culto y civilizado" de la ciudad comparando su actitud con la de los conquistadores del nuevo mundo.

Cuando ven al hombre de nuestros campos, al modesto agricultor, envuelto en su manta de lana o con un poncho a la espalda, les parece que ven al indio de nuestras

Pampas, a quien se creen autorizados para tratar con la misma dureza e injusticia que los conquistadores empleaban con los primitivos habitantes de la América. (Hernández, 1987: 107)

La visión positiva del "otro", símbolo de la cultura y del progreso que nos dan los autores rómanticos, en las décadas siguientes será diferente ya que también cambiará la posición que ocupaban los 
inmigrantes en la sociedad argentina. La inicial admiración será sustituida por los conflictos entre nativos y extranjeros, conflictos surgidos de la competencia en el ámbito laboral. Los "otros" fueron atraídos para poblar, mientras el panorama rural sufrió cambios radicales. La tierra estaba en manos de pocos, la ganadería no necesitaba muchas más manos de obra, de hecho, como en este trabajo los inmigrantes destacaban más bien por falta de habilidad, se les ofrecía trabajos en la agricultura. Ante esa situación muchos de los inmigrantes se quedaban en las ciudades. Si en el pasado las ciudades estaban habitadas mayoritariamente por la élite criolla, a partir de la década de los 80 empezaron a poblarse de los inmigrantes.

Una vez finalizado el conflicto entre gauchos y criollos apareció otro conflicto, entre proletarios o arrendatarios contra los terratenientes.

Una curiosa voz en el debate literario acerca del papel creativo o destructor del "otro" la alzaron unos autores que pertenecían a la élite argentina que habían vivido y visto con sus propios ojos aquella realidad de grandes cambios sociales. Como buenos hijos de las familias influyentes hicieron una carrera militar, al mismo tiempo recibieron buena formación para destacar en los años posteriores en el mundo artístico y cultural, también en el mundo literario. En sus obras reflexionan sobre la vida en Argentina comparando la actualidad con el pasado. Retroceden en el tiempo para valorar las condiciones de vida, desde la óptica de los representantes de la aristocracia, para la que los postulados de la igualdad entre hombres fueron difíciles de entender, lo mismo que aceptar la presencia de tantos inmigrantes en la sociedad argentina que estaban reclamando sus derechos como ciudadanos.

En Mis Memorias publicadas en 1904, Lucio V. Mansilla describe el mundo que se acaba. En sus palabras los inmigrantes constituyen un peligro para la identidad nacional, les acusa de ser partidarios de las ideas de Rosas porque fueron los únicos privilegiados durante la dictadura.

Ya no sólo hemos vivido, sino que la inmigración nos ha envuelto. 
Con su incorporación activa, incesante a nuestra vida social en todas sus manifestaciones, particularmente en Buenos Aires, donde, por decirlo así, se fragua, no tanto el sentimiento cuanto la opinión nacional, poco a poco se ha ido formando un juicio anónimo favorable al gobierno de Rosas.

Las facultades extraordinarias no se ejercían contra el extranjero, que tenía siempre detrás al cónsul, al ministro, los cañones de la bandera. El gringo, como regla casi sin excepción, ocupaba una posición favorecida. (Mansilla, 1955: 105)

Con sus palabras muestra la verdadera disposición de las élites argentinas ante los extranjeros, que resultó ser opuesta a la de las voces de los teóricos. La participación activa del inmigrante en la vida social fue un inconveniente para la alta clase criolla.

Con un tono similar escribía Santiago Calzadilla, otro representante de las élites, quien en Las Beldades de mis tiempos también dirige su mirada hacia el pasado recordando con un tono nostálgico los viejos tiempos. Utiliza la figura del gaucho, que en aquellos tiempos ${ }^{4}$ ya fue un ser legendario, como pretexto para fomentar la hostilidad hacia los extranjeros, a los que consideraba culpables de todas las desgracias y problemas de Argentina.

Pero huyamos del tiempo presente a donde nos arrastra la idea de los males que nos aquejan, y vamos a los de bonanzas, que son los pasados, siempre en los barrios del sur, en donde vivían tantos tipos ingénitos, cuyo recuerdo con aquellas criollas traen sonrisas a los labios, que a la par del gaucho legendario desaparecen - ante los gringos insulsos e interesados que vienen con otras costumbres y necesidades - con la actual civilización que no necesita de ese hombre de fierro que en medio de la pampa desprendía su lazo y aprisionaba al animal bravío, que se había criado en plena libertad sin acercarse a las poblaciones ni ver gentes. (Calzadilla, 1944: 28)

En las últimas décadas del siglo XIX, debido a las estrechas relaciones que Argentina mantenía con Francia, llegaron a Hispanoamérica las obras de los principales novelistas del realismo- naturalismo

\footnotetext{
${ }^{4}$ La obra Las Beldades de mis tiempos fue publicada en 1919.
} 
europeo, que encontraron un buen público y seguidores entre los jóvenes escritores argentinos de la así llamada generación del $80 .^{5}$

En sus obras, los autores pretendían analizar de una manera objetiva los problemas presentes en la sociedad de aquel entonces, aprovechando el análisis para fines didácticos.

En las páginas de las novelas revive el viejo conflicto entre la civilización y la barbarie. Sólo que esta vez la barbarie reside en la población inculta, que ya no habita solamente en el interior del país. Ha entrado en las ciudades por medio de los inmigrantes.

Europa ha dejado de ser el único hábitat de la civilización. La parte civilizada de la sociedad la forman los miembros de la antigua aristocracia de la descendencia criolla, mientras que los bárbaros son los europeos.

El propio Sarmiento, uno de los primeros que postulaban fomentar la inmigración de fuera y con su trabajo político y de escritor defendía la presencia europea en Argentina, medio siglo más tarde advierte sobre los peligros que constituye tener tantas personas de fuera en un país con una identidad en formación. En su ensayo Conflictos y armonías de las razas de América del año 1883 alza la voz de alarma contra determinados tipos de inmigrantes.

La política proinmigratoria que suponía un transplante de civilización, en vez de aportarla trajo como consecuencia un conglomerado de etnias diversas que, en vez de asimilarse, empezaron a crear respectivas colonias nacionales en el suelo argentino.

Planteándose la pregunta acerca de la identidad nacional, Sarmiento como respuesta señala esta amalgama de orígenes de los nuevos americanos y de los nuevos argentinos, que hace imposible hablar de una identidad propia y común para todos.

¿Qué es la América?

${ }^{5}$ Eligieron esta simbólica fecha que les identificaba como un grupo artístico con ideas diferentes a las de la anterior generación del 37, ya que en 1880 fue definitivamente consolidada la posición de la ciudad de Buenos Aires como la capital de la República. 
Es acaso ésta la vez primera que vamos a preguntarnos quiénes éramos cuando nos llamaron americanos, y quiénes somos cuando argentinos nos llamamos.

¿Somos europeos? - ¡Tantas caras cobrizas nos desmienten!

¿Somos indígenas? - Sonrisas de desdén de nuestras blondas damas nos dan acaso la única respuesta.

¿Mixtos? -Nadie quiere serlo, y hay millares que ni americanos ni argentinos querrían ser llamados.

¿Somos Nación? ¿Nación sin amalgama de materiales acumulados, sin ajuste ni cimiento?

¿Argentinos? Hasta dónde y desde cuándo, bueno es darse cuenta de ello. (Sarmiento, 1883: 14)

Esta línea del pensamiento podemos observarla en los posteriores artículos de Sarmiento, que fueron agrupados con el título Condición del extranjero en América, en las que varias veces el autor advierte del peligro de seguir con la política proinmigratoria que lleva a la desintegración de la sociedad.

Las críticas más duras recaen sobre los italianos, por ser una de las comunidades más numerosas y formar un grupo completamente aislado.

El convencimiento de que "el otro" no necesariamente debería formar parte de la sociedad argentina, ya que en vez de aportar valores ni siquiera es capaz de adaptarse a la vida en el Nuevo Mundo, lo demuestran los escritores de la época.

Las obras de los representantes de la generación del 80 muestran la existencia de cierto xenofobismo y prejuicio racial en estos jóvenes clasistas de las viejas familias hacia la nueva burguesía formada en gran parte por los inmigrantes.

Los autores aprovechan los postulados literarios del determinismo biológico para justificar las existentes barreras sociales. Usan la técnica naturalista para mostrar la influencia negativa de los inmigrantes en la sociedad argentina. Lo mismo que en los textos teóricos, en la ficción la discriminación está presente sobre todo en la descripción de 
los italianos y también de los judíos que son tomados como objeto de prejuicios.

El símbolo de la sangre, que constituye el orgullo familiar y es el rasgo racial que diferencia en la sociedad, lo adopta como título Eugenio Cambaceres, en su novela En la sangre.

Cambaceres se sirve de la hipótesis naturalista de la herencia y la determinación en dos dimensiones; la individual, a la hora de describir a los protagonistas, y la simbólica. Hablando de Genaro dice:

Víctima de las sugestiones imperiosas de la sangre

De la irresistible influencia hereditaria, del

Patrimonio de la raza que fatalmente con la vida, al

Ver la luz, le fuera transmitido, las malas, las

Bajas pasiones de la humanidad hicieron de pronto explosión en su alma.

(Cambaceres, 1984: 103)

La vida de Genaro sirve de pretexto para mostrar los efectos negativos de la inmigración. Al usar la palabra italiano, el autor no se refiere sólo a la nacionalidad. Esta palabra contiene toda la lista de significados negativos, es sinónima de avaricia, de brutalidad, de ignorancia. Desvaloriza no sólo al personaje, sino a todos los inmigrantes.

La crisis de los años 90, que afectó a la sociedad argentina aumentó aún más la actitud de rechazo hacia los de fuera viendo en ellos al causante de todas las maldades. Esta visión del "otro" nos la ofrece Julio Martel en su novela La Bolsa. La imagen que tiene Martel sobre la inmigración masiva equivale a la opinión del sector aristocrático. La decadencia física y moral del tipo argentino es efecto de la inmigración. En el libro, el doctor Glow es el portavoz del autor, según el cual el judío es el causante de la ruina económica del país.

¿Por qué no trabaja el judío? ¿Por qué hacía alarde de no haber empuñado nunca el arado, de no haber sido nunca agricultor, ni haber ejercitado jamás ninguna profesión útil? Vampiro de la sociedad moderna, su oficio es chuparle la sangre - decía el doctor manoteando- El es quien fomenta la especulación, quien aprovecha el fruto del trabajo de los demás... Banquero, prestamista, especulador, nunca ha sobresalido en las letras, en 
las ciencias, en las artes, porque carece de la nobleza de alma necesaria, porque le falta el ideal generoso". (Martel, 1946: 124)

Antonio Argerich, en la novela ¿Inocentes o culpables?, saca las mismas conclusiones acerca del futuro del país; habrá que restringir la entrada a Argentina, seleccionar a los que puedan llegar en el futuro pues de lo contrario el país volverá a la barbarie. El protagonista de la obra José Daigore, lo mismo que el ya mencionado Genaro de Cambaceres, está determinado por su herencia, por los malos genes de sus antepasados que "no habían ejercitado sus cerebros en muchas generaciones y, por tanto, no podían transmitir ninguna buena disposición para el franco vuelo del pensamiento" (Argerich, 1984: 243).

La figura del otro entró tan profundamente en el mundo literario que entre las obras clásicas argentinas podemos diferenciar un género especial llamado la novela del inmigrante, que se inscribe dentro de la corriente de la novela realista.

La novela del inmigrante presenta varios enfoques temáticos entre los que podemos diferenciar: obras cuya trama se desarrolla en diversos contextos en los que aparecen los inmigrantes - la gran parte de las historias se desarrolla dentro de la ciudad, aunque hay novelas ambientadas en la pampa o en la costa argentina.

Otro grupo lo constituyen las novelas que muestran las aventuras de diversos grupos étnicos o nacionales. En este caso la mayoría de los protagonistas de origen extranjero procedía de Italia o España, o tenía raíces judías.

En las novelas podemos seguir varios momentos en la vida del "otro" desde su llegada a Argentina, los primeros intentos de encontrar su lugar en la nueva realidad tan ajena a lo conocido, hasta observar la historia de las futuras generaciones de los hijos ya nacidos en el suelo argentino, que muchas veces no saben valorar el pasado de sus padres y rechazan su herencia.

En cuanto a la novela urbana, la ciudad que está más presente en las obras literarias es Buenos Aires, algo que no debe sorprender ya que el gran número do los recién llegados se asentaba en la capital. Los inmigrantes se instalaban en casas abandonadas por la aristocracia 
criolla llamadas conventillos, en las que las condiciones de vida dejaban mucho que desear ya que sus inquilinos eran gente de bajos fondos sociales que no disponían del dinero suficiente para poder siquiera reparar las casas.

¿Cómo era la vida en el conventillo? Así la describe Silverio Domínguez alias Ceferino de la Calle en su novela Palomas y gavilanes:

La casa de inquilinato presentaba un cuadro animado, lo mismo en los patios que en los corredores. Confundidas las edades, las nacionalidades y los sexos, constituía una especie de gusanera, donde todos se revolvían, saliendo unos entrando otros, cruzando los más, con esa actividad diversa del conventillo.

Húmedos los patios, por allí se desparramaba el sedimiento de la población; estrechas celdas, por sus puertas abiertas se ve el mugriento cuarto, lleno de catres y baúles, sillas desvencijadas, mesas perniquebradas, con espejos enmohecidos, con sus cuadros almazorronados, con sus periódicos de caricaturas pegados a la pared, y ese peculiar desorden de la habitación donde duermen cuatro o seis, y en donde es preciso dar buena o mala colocación a todo lo que se tenga.

Delante de las puertas, hierven las ollas de hierro con la cabeza de capón o la magra carnaza de puchero, o salta la grasa al freír las piltrafas del mercado que despiden acre color, mondaduras de papas, desperdicios de cebolla y hojas medio secas de repollo, parece que limitasen el dominio de la pieza, o su opción al pedazo de patio, como un alambrado limita el campo de un estanciero en la inmensa sábana de la pampa.

El agua de jabón forma numerosos regueros que se pierden en el suelo, bien entre las junturas de las baldosas, o se cuelan por los agujeros de desagüe, cayendo constantemente de las bateas donde se lava la ropa mugrienta, que despide nauseabundo olor.

En cuerdas que van de uno a otro extremo del patio, suspendidas por cañas en el centro, se tienden las sábanas mojadas, los pañales sucios por el orín, las camisas plomizas y alguno que otro remendado colchón, 
para secar la fresca mojadura de la noche pasada. (Ceferino de la Calle, 1886: $100-101)^{6}$

En el contexto urbano ambientaron sus novelas, entre otros, los ya mencionados autores como Julio Martel, Eugenio Cambaceres, Antonio Argerich.

Dentro de la corriente de la novela de la pampa destacan los libros de Manuel Ugarte y José Adolfo Gaillardon.

En cuanto al origen de los protagonistas, entre los inmigrantes predominan los que venían de Italia. Igual que en la vida real, ya que los italianos a finales del siglo XIX superaron en cantidad a todos los demás inmigrantes que llegaron a Argentina. De origen italiano son Genaro y José Diagore cuyas vidas cuentan Eugenio Cambaceres y Antonio Argerich respectivamente.

A la inmigración italiana le siguió en número la inmigración de la península ibérica, lo que también encontró su reflejo en la ficción literaria. El autor que describió principalmente la comunidad española fue Francisco Grandmontagne, él mismo de origen inmigrante.

Otro grupo étnico que aparece a menudo en la literatura de aquellos tiempos son los judíos, que protagonizan las obras de Alberto Gerunchoff, 7 entre otros.

Aparte de la división geográfica o étnica existe también otro criterio que permite diferenciar una corriente más dentro del género de la novela del inmigrante. Se trata del momento en el que nos encontramos con el protagonista. Si en las primeras obras se contaban las aventuras de los recién llegados, con el tiempo los autores describirán la vida de las siguientes generaciones, de los hijos nacidos en Argentina.

Entre ellos, habrá personajes que se inscriben dentro de la línea de la novela naturalista, condenados al fracaso debido a sus orígenes,

\footnotetext{
${ }^{6}$ Varios autores coinciden en las descripciones de la vida en el conventillo que por primera vez apareció en la novela Antígona de Roberto Payró.

${ }^{7}$ Son solamente unos ejemplos que muestran las principales tendencias en la literatura argentina de finales del siglo XIX., ya que no es el objeto de este artículo hacer un trabajo bibliográfico ni mencionar todos los autores de la época. Para más detalle véase Onega (1965), García (1970).
} 
a proceder de familias incultas de bajas capas sociales. Por mucho esfuerzo que hicieran no podían triunfar en la sociedad ya que sus malos genes determinaban su futuro (p.ej. Genaro de En la sangre de Cambaceres o José Diagore de ¿Inocentes o culpables? de Argerich).

Por otro lado, hay protagonistas que encontraron su lugar en la nueva realidad e incluso triunfaron en el mundo laboral, lograron un avance social, aunque para hacerlo rechazaron su identidad y olvidaron sus raíces (es el caso de los protagonistas de las novelas de Grandmontagne).

También existen novelas que muestran la vida de varias generaciones, dentro del género de la novela de la transformación social. La primera es la generación de los inmigrantes, que abandonaron su patria para encontrar una vida mejor en Argentina, dispuestos a trabajar duro para asegurar el futuro a sus hijos. Pero resulta que muchas veces los hijos nacidos en Argentina no son capaces de valorar el esfuerzo de sus padres. Para asimilarse tratan de apartarse del pasado de la familia, lo que a la larga los lleva a una pérdida de la herencia de sus padres. Será la tercera generación, la de los nietos, quienes sí saben apreciar la historia de sus antepasados, la respetan, aunque en el fondo se sienten más argentinos que europeos.

Si al inicio "el otro" aparecía en las novelas sólo en algunos episodios, con el tiempo se convirtió en el protagonista principal. Italianos, españoles, judíos, alemanes, británicos, franceses llenaron las páginas de las novelas igual que en el mundo real, ya que a finales del siglo XIX la sociedad argentina estaba formada en gran parte por los descendientes de inmigrantes de todo el mundo. Uno de los mejores retratistas de este mosaico argentino fue José Sixto Álvarez alias Fray Mocho quien en sus cuentos muestra la sociedad de sus contemporáneos donde nadie puede ser llamado "el otro", ya que todos tienen por lo menos uno o más inmigrantes en la historia de la familia. Así es el caso de los protagonistas de uno de sus cuentos En familia, en el que el padre se queja de la imposibilidad de poder comunicarse con sus yernos ya que cada uno habla una lengua diferente: 
¡Caramba!... Ya mi casa, che, no es mi casa... más parece coche e?? tragüay o pasadizo del hotel. ¡Mira! ... Por esta cruz, ¿ves?... yo cada vez que tengo que hablar con alguno de mis yernos, 'le juego señas no más y pura arrugada y cara, pa que vean que yo no estoy enojado... pero no les entiendo ni un pito... No. che. ¡convencete!... lo pior que $\mathrm{n}$-'c puede pasar a una familia, es lo que nos pasa a nosotros... La primera que 'comenzó fué Julia con su alemancito.' y de áhi siguieron no más como lienzo de alambrao. Petrona eón su italiano. Antonia ron su portugués. Eulogia con su inglesito y áura se nos viene Susana con un francés... ¡No. che, no ... a no embromar vamos!... i, No faltaba más! (Fray Mocho, 1906)

Los tonos hostiles hacia los inmigrantes, que aparecieron en las obras de los escritores de la generación del 80, cambiaron en la obra de los positivistas argentinos, que intentaron hacer un análisis frío de los procesos que llevaron a la formación de la nacionalidad argentina y describían la sociedad ofreciendo una visión favorable de los inmigrantes.

Con ocasión del famoso Centenario del año 1910 muchos intelectuales intentaron contribuir en la discusión acerca de la identidad y en varios textos teóricos evocaban la figura del "otro" y el papel que desempeñó en la historia de Argentina.

En Las multitudes argentinas José Ramón Mejía analiza el fenómeno de la inmigración comparándola a la evolución de los organismos biológicos. Lo mismo que en el mundo de la naturaleza, en la sociedad también son necesarios años para que un elemento se incorpore y forme parte integral de una totalidad transformándola a la vez con su presencia. Según el autor el inmigrante anuncia la llegada de los nuevos tiempos, de una transformación de la vieja raza argentina.

Otra voz en el debate acerca de la argentinidad es la de Carlos Octavio Bunge en su ensayo Nuestra América, en el que analiza el carácter del hombre americano, que es resultado de la mezcla de elementos de procedencia indígena, africana y española, y cuyos rasgos no son de todo positivos. El autor retoma la antigua idea sarmientina

\footnotetext{
${ }^{8}$ Cit. por Germán García (1970: 61-62).
} 
sobre la capacidad de asimilar la cultura de fuera. Y el remedio que propone a la sociedad es europeizarse (Onega, 1965: 78-82).

En el debate acerca del Centenario no podía faltar la voz de José Ingenieros, gran intelectual de aquellos tiempos, él mismo fue de origen inmigrante, quien en su serie de artículos titulados La sociología argentina divaga sobre el fenómeno migratorio. Según él, la humanidad se desarrolla a través de la lucha de razas, en la que la inmigración representa la expansión de la raza blanca.

La formación de la nacionalidad argentina - y de todos los países americanos, primitivamente poblados por razas de colores es en su origen un simple episodio de la lucha de razas ... en la historia de la humanidad podría figurar en el capítulo que estudiara la expansión de la raza blanca, su adaptación a nuevos ambientes naturales y la progresiva preponderancia de la civilización donde esa adaptación ha sido posible. (Ingenieros, 1957: 26)

"La "europeización" no es, en nuestro concepto, un deseo, (..) es un hecho inevitable en las zonas templadas, habitables por las razas blancas, que se produciría, aunque todos los hispanoamericanos quisieran impedirlo". (Ingenieros, 1957: 105)

Aunque los primeros cien años en la historia de Argentina llevaron a la formación de un estado políticamente independiente de la corona española, durante todo ese tiempo los argentinos se enfrentaron a ciertas dificultades a la hora de intentar definir el concepto de la nación. La pregunta acerca de la identidad propia fue una de las principales cuestiones tratadas en los debates de los intelectuales, planteada aún más veces con ocasión del Centenario. El inicio del siglo XX demostró que el sueño sarmientino de poblar las vastas tierras argentinas con los colonos de proveniencia europea fue un hecho, sin embargo, el perfil de inmigrantes asentados en Argentina no necesariamente se adecuaba a los ideales de los políticos. La nación argentina estaba compuesta mayoritariamente por los hijos de los inmigrantes de muchos rincones de Europa, en cierta parte por las familias de las antiguas élites criollas, en una mínima parte por descendientes de los habitantes 
autóctonos de esa tierra. En este crisol de razas y culturas ya nadie podía ser llamado "el otro" porque todos juntos, con sus rasgos propios y pocas similitudes, identificaban a la naciente nación argentina.

Como en la vida misma, este proceso de lenta aceptación del que venía de fuera está visible en la literatura. Al inicio, el "otro" aparecía sólo en algunos episodios, como un ser ajeno e incomprendido en la sociedad debido a su comportamiento, su manera de hablar, etc. A veces objeto de burla por ser diferente, aunque con el tiempo cada vez más apreciado. El cambio gradual en la percepción del "otro" fue debido al convencimiento cada vez más presente en la sociedad argentina de que todos los que venían de Europa eran portadores de valores y conocimientos. Esta línea de pensamiento podemos observarla en las obras de los románticos.

Sin embargo, la positiva visión del "otro" con el tiempo fue sustituida por tantas descripciones negativas, ya que la segunda mitad del siglo XIX trajo cierta decepción en cuanto al papel que podían desempeñar los inmigrantes en el proceso de creación del estado argentino.

Los esperados portadores del progreso y de la sabiduría resultaron ser unos simples trabajadores que lo único que podían ofrecer a su nueva patria eran las manos dispuestas a trabajar. El mundo de los conventillos, poblados por pobres obreros de diversa descendencia fue descrito por los naturalistas argentinos en sus novelas.

A finales del siglo XIX se alzan más voces que añoran la Argentina del pasado, la Argentina de las pampas llenas de ganado, los tiempos del mítico gaucho, que de repente, de ser símbolo de atraso e incultura se convirtió en el emblema de la verdadera nación argentina. Son voces de los representantes de antiguas élites, que en la presencia de tantos inmigrantes veían una amenaza para su posición privilegiada en la sociedad.

Pero ya no era posible parar el flujo migratorio y volver al pasado. Aunque las leyes que intentaban prohibir la entrada al " inmigrante no deseado" lograron limitar el número de los que arribaban a las costas de la Plata, la europeización de la sociedad argentina fue un hecho. En los escritos de los autores del inicio del siglo los inmigrantes no son personajes episódicos, sino que protagonizan las obras. No destacan 
por ser diferentes en la sociedad ya que forman una parte integral de ella. Es cada vez más difícil llamar a alguien "el otro" ya que "los otros" llegaron a ser argentinos.

\section{Bibliografía}

ARGERICH, A. (1984), ¿Inocentes o culpables?, Hyspamérica, Buenos Aires. CALZADILLA, S. (1944), Las beldades de mi tiempo, Ángel Estrada, Buenos Aires.

CAMBACERES, E. (1984), En la sangre, Editora Nacional, Madrid.

CALLE, C. (1886), Palomas y gavilanes, Félix Lajouane, Buenos Aires.

GARCÍA, G. (1970), El inmigrante en la novela argentina, Librería Hachette, Buenos Aires.

HERNÁNDEZ, J. (1987), Martín Fierro, Cátedra, Madrid.

INGENIEROS, J. (1957), Obras completas, Vol. 8: Sociología argentina, Ed. Elmer, Buenos Aires.

MANSILLA, L. (1955), Mis memorias. (Infancia y adolescencia), Librería Hachette S.A., Buenos Aires.

MARTEL, J. (1946), La bolsa, Estrada, Buenos Aires.

ONEGA, G. (1965), La inmigración en la literatura argentina (1880-1910), La Imprenta de la Universidad Nacional del Litoral, Santa Fe.

SARMIENTO, D.F. (1883), Conflictos y armonías de las razas en América, Imprenta de D. Túnez, Buenos Aires.

SARMIENTO, D.F. (1986), Facundo, Cátedra, Madrid. 